NASZA DERMATOLOGIA Online OUR DERMATOLOGY Online

Source of Support: Nil

Competing Interests: None

\section{NEONATAL OCCIPITAL ALOPECIA IN A NEWBORN}

\author{
Anca Chiriac ${ }^{1}$, Anca E Chiriac ${ }^{2}$, Piotr Brzezinski ${ }^{3}$
}

${ }^{1}$ Department of Dermato-Physiology, Apollonia University Iasi, Strada Muzicii nr 2, Iasi-700399, Romania

${ }^{2}$ University of Medicine and Pharmacy "Gr. T. Popa" Iasi, Romania

${ }^{3}$ Department of Dermatology, 6th Military Support Unit, Ustka, Poland

Corresponding author: Prof. Anca Chiriac, MD PhD

ancachiriac@yahoo.com

Our Dermatol Online. 2014; 5(3): 297

Date of submission: 28.03 .2014 / acceptance: 30.04 .2014

Chiriac A, Chiriac AE, Brzezinski P. Neonatal occipital alopecia in a newborn. Our Dermatol Online. 2014; 5(3): 297.

A newborn, male gender, born at term, APGAR 10, was addressed to us for occipital alopecia observed since birth (Fig. 1). Mother was a young health person of 25 years old, primipara and the birth was non-Caesarian delivery. Alopecia was confirmed in the occipital area, with no signs of inflammation or other dermatological problems on the whole body. A diagnosis of frictional/pressure occipital alopecia was admitted and the family was reassured of the absence of any inquiry. No followup was recommended.

Since the alopecia was confirmed during the first days of life of the infant the problem of friction/pressure during sleep was questioned.

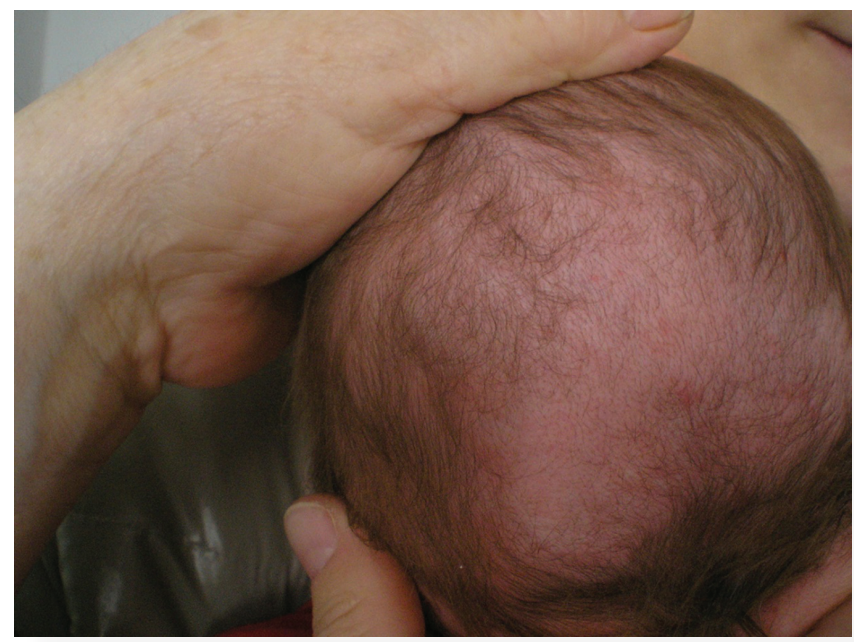

Figure 1. Neonatal occipital alopecia in a newborn.
Looking through the literature: neonatal occipital alopecia was first described by Brocq long time before in 1907 [1]; since then, reports have been published and data showed a prevalence of 9-12\% [2], especially in Caucasian children [3].

It is a non-scarring alopecia, localized-type, described mostly in infants of 2-3 months old [3].

The cause of this type of alopecia remains a subject of debate: induced by pressure/friction during sleeping [4], being an acquired form of alopecia or a physiologic process of hair shedding started during gestation [5]. The present case of neonatal occipital alopecia diagnosed in the first day of life support the second opinion of a physiologic process started in utero. Further opinions and studies are necessary to clarify the question.

\section{REFERENCES}

1. Brocq L. Traite elementaire de dermatologie pratique. Paris: Octave Doin; 1907:358.

2. Cutrone M, Grimalt R. Transient neonatal hair loss: a common transient neonatal dermatosis. Eur J Pediatr. 2005;164:630-2.

3. Rogers M. Hair loss in the neonate. In: Eichenfield LF, Frieden IJ, Esterly NB, editors. Textbook of neonatal dermatology. 1st ed. St. Louis: Mosby; 2001:494.

4. Chang MW, Orlow SJ. Neonatal, pediatric, and adolescent dermatology. In: Freedberg IM, Eisen AZ, Wolff K, Austen KF, Goldsmith LA, Katz SI, editors. Fitzpatrick's dermatology in general medicine. 7th ed. New York: McGraw-Hill; 2008:935-55.

5. Kim MS, Na CH, Choi H, Shin BS.. Prevalence and Factors Associated with Neonatal Occipital Alopecia. Ann Dermatol. 2011;23:288-92.

Copyright by Anca Chiriac, et al. This is an open access article distributed under the terms of the Creative Commons Attribution License, which permits unrestricted use, distribution, and reproduction in any medium, provided the original author and source are credited. 